\title{
Does Mendeley provide evidence of the educational value of journal articles? ${ }^{1}$
}

Mike Thelwall,

Statistical Cybermetrics Research Group, University of Wolverhampton, UK.

Research articles seem to have direct value for students in some subject areas, even though scholars may be their target audience. If this can be proven to be true, then subject areas with this type of educational impact could justify claims for enhanced funding. To seek evidence of disciplinary differences in the direct educational uptake of journal articles, but ignoring books, conference papers and other scholarly outputs, this paper assesses the total number and proportions of student readers of academic articles in Mendeley across 12 different subjects. The results suggest that whilst few students read mathematics research articles, in other areas the number of student readers is broadly proportional to the number of research readers. Although the differences in the average numbers of undergraduate readers of articles varies by up to 50 times between subjects, this could be explained by the differing levels of uptake of Mendeley rather than the differing educational value of disciplinary research. Overall, then, the results do not support the claim that journal articles in some areas have substantially more educational value than average for academia, compared to their research value.

Key points:

- There are wide disciplinary differences in the numbers of student Mendeley readers per article.

- There are narrow disciplinary differences in the ratios of student to researcher Mendeley readers per article.

- Evidence from Mendeley does not support the hypothesis that articles from some subject areas have more educational value than articles from most other subject areas.

\section{Introduction}

Scientific publications have been traditionally viewed as the building blocks of collective human understanding. From this perspective, citations from future publications are useful evidence of the value of an output because they suggest that the work has been built upon, further adding to knowledge (Merton, 1973). In the arts and humanities, this model is less relevant because scholars may value new perspectives rather than the pursuit of the truth (Becher \& Trowler, 2001; Whitley, 2000) and research in many or all subject areas is partly driven by societal needs. In particular, the information embedded in academic publications from all disciplines may also be useful to society to inform professional practice, drive industrial or organisational innovations, improve health, develop culture and educate the workforce. This article focuses on the last of these by comparing the extent to which journal articles from different disciplines are read by students. Given the lack of a direct relationship between teaching success and research achievements at the level of individual scholars or

\footnotetext{
${ }^{1}$ Thelwall, M. (in press). Does Mendeley provide evidence of the educational value of journal articles? Learned Publishing. doi:10.1002/leap.1076
} 
groups of scholars (Hattie \& Marsh, 1996; Verburgh, Elen, \& Lindblom-Ylänne, 2007), and an apparently common belief that disciplinary research should inform teaching (e.g., Jenkins, Healey, \& Zetter, 2007) this may give useful new insights into the educational impact of disciplinary research at the level of publications. If there are clear differences, then this would help areas producing such additional educational value justify their share of national research funding. This is a separate issue to the use of research into teaching practice (Ambrose, Bridges, DiPietro, Lovett, \& Norman, 2010).

Higher education syllabi are presumably informed by disciplinary research, although the amount and nature of the influence may vary by subject. At one extreme a postgraduate module may be based around critiquing a set of recently published journal articles or monographs, and in fast moving subjects, the ability to read and understand academic publications is a relevant professional skill (Caldwell, Henshaw, \& Taylor, 2011). At the other extreme, some modules might revolve around skills, such as mastering software and equipment, tacit or professional knowledge, such as courtroom etiquette. Knowledge might also be transmitted via textbooks, with scholars translating traditional academic outputs into a pedagogical format (Horsley, Knight, \& Huntly, 2010; Hyland, 2004; Myers, 1992). In some disciplines, textbooks may present a subject's accepted core knowledge (Lynch \& Bogen, 1997). Less directly, higher education lecturers in many countries and subjects are expected to be certified doctorate researchers, or equivalent, and their teaching presumably transmits their research-informed understanding of their discipline even if it does not directly translate published research.

Although not directed at this goal, previous studies have provided evidence about disciplinary differences in the uptake of academic research outputs. One logical source is the academic syllabus because this routinely contains lists of documents for students to read (O'Brien, Millis, \& Cohen, 2009). An investigation of citations to journal articles in online syllabi found that these occurred only $10 \%$ as frequently as Web of Science (WoS) citations in the social sciences (i.e., there were 10 WoS citations for every syllabus citation), $3 \%$ as numerous in engineering, but between $0.01 \%$ and $0.5 \%$ as numerous in natural, life and formal sciences (Kousha \& Thelwall, 2008). On average, half of all social science journal articles were included in reading lists, in comparison to $9 \%$ for engineering, and $1-3 \%$ for the natural, life and formal sciences, with the exception of multidisciplinary sciences (12\%). This study did not include the arts, humanities and medicine and was limited by analysing only online academic syllabi. Nevertheless, it provides strong evidence that there are substantial disciplinary differences in the educational uses of academic research. An alternative source of information about student reading is the documents that they register in a social reference sharing site, such as Mendeley, that allows users to add and share lists of academic references. A previous study of different types of Mendeley reader has reported small broad disciplinary differences in the proportions of student readers of articles from 2012, as recorded in Mendeley (Mohammadi, Thelwall, Haustein, \& Larivière, 2015). For undergraduates (Bachelor Student) the proportions were 2.8\% (Engineering and Technology), 3.0\% (Social Sciences), 1.4\% (Physics), 2.4\% (Chemistry) and 3.5\% (Clinical Medicine). For postgraduate students the proportions were $17.4 \%$ (Engineering and Technology), 19.5\% (Social Sciences), 9.6\% (Physics), 11.1\% (Chemistry) and 12.6\% (Clinical Medicine). This suggests that few undergraduates read recent research in any discipline, or they do not use Mendeley, and that there are disciplinary differences in the proportions of postgraduates reading recent research. This study was limited by Mendeley at the time reporting the three largest categories, which would affect the small undergraduate category 
in particular (Haustein \& Larivière, 2014). It also did not cover any arts and humanities subjects. Another paper compared the proportions of articles with any type of Mendeley reader across different subjects, finding humanities readership (40.7\%) to be lower than average (66.2\%) but arts readership to be exactly average for all areas of scholarship (Haustein, Larivière, Thelwall, Amyot, \& Peters, 2014).

The studies reviewed above have provided evidence of the differing educational values of published academic research, but have technical limitations and have not covered the arts and humanities. The current study fills this gap by analysing disciplinary differences in the proportion of Mendeley readers of academic outputs in different disciplines, including from the arts and humanities. Mendeley (Gunn, 2013) was chosen as the source of raw data because of its inclusion of data about numbers of student members expressing an interest in academic articles. Although the current study also has substantial technical limitations, its goal is to provide additional evidence to support the important claim that some disciplinary areas have more direct educational value than others.

\section{Research Questions}

Higher education institutions typically distinguish between research-based degrees, such as doctorates and the MPhil, and taught degrees, such as undergraduate courses, the MA and the MSc. Even though taught causes can contain an element of research in the form of a dissertation, this is typically a minor part of undergraduate courses and a third of master's degree level courses. In addition, undergraduate dissertations foster independent learning and may not generate new knowledge, although this is also possible (Greenbank \& Penketh, 2009; Todd, Bannister, \& Clegg, 2004). Undergraduate and, to some extent, master's student reading can therefore be expected to be primarily for education rather than research. Conversely, even though some countries include a taught component within their $\mathrm{PhD}$ programmes, doctoral studies overall are driven by research. This article therefore focuses on disciplinary differences in the proportion of articles read by non-research students. The restriction to journal articles is a practical one to focus on one type of research output, even though books, conference papers and other outputs are more important in some areas of academia.

- RQ1: Are there differing numbers of undergraduate Mendeley readers of academic articles between subjects?

- RQ2: Are there differing numbers of master's degree student Mendeley readers of academic articles between subjects?

A limitation of the above research questions is that the take-up of Mendeley varies by discipline (Van Noorden, 2014) and so low numbers of Mendeley readers could be due to low levels of readership or low levels of Mendeley use. To address this issue, the proportion of non-research readers of articles also needs to be assessed. Assuming that the relative uptake of Mendeley between researchers and non-researchers does not vary substantially between disciplines, although it clearly does vary, the results should give evidence of disciplinary differences in the relative worth of articles between taught and research contexts.

- RQ3: Are there differing proportions of undergraduate Mendeley readers of academic articles between subjects?

- RQ4: Are there differing proportions of master's degree student Mendeley readers of academic articles between subjects? 


\section{Methods}

The research design is to compare the numbers and proportions of Mendeley student readers of articles in fields from a range of different areas of scholarship. There is no agreed categorisation of academic subjects and so a collection of twelve different fields was chosen to represent different broad areas of research (Table 1). Scopus subject categories were selected to delimit each field. These allocate academic journals into one or more relatively specific fields and are a convenient way of identifying large sets of articles with a similar focus. Although Scopus categories are imperfect and there are alternatives (e.g., Glänzel \& Schubert, 2003), their inaccuracies do not undermine their use for comparing broad areas of scholarship.

Table 1. The twelve narrow Scopus subjects chosen for analysis and the number of articles selected in each one (capped at 10,000).

\begin{tabular}{|l|l|l|r|}
\hline Broad area & Scopus broad subject & Scopus narrow subject & Articles \\
\hline $\begin{array}{l}\text { Life sciences } \\
\text { (applied) }\end{array}$ & $\begin{array}{l}\text { Agricultural and } \\
\text { Biological Sciences }\end{array}$ & Agronomy and Crop Science & 9852 \\
\hline Humanities & Arts and Humanities & History & 6967 \\
\hline Arts & Arts and Humanities & Visual Arts and Performing Arts & 6096 \\
\hline Life sciences (pure) & $\begin{array}{l}\text { Biochemistry, Genetics } \\
\text { and Molecular Biology }\end{array}$ & Aging & 2666 \\
\hline $\begin{array}{l}\text { Natural science } \\
\text { (pure) }\end{array}$ & Chemistry & Analytical Chemistry & 10000 \\
\hline Computing & Computer Science & Artificial Intelligence & 9909 \\
\hline Engineering & Engineering & Aerospace Engineering & 7155 \\
\hline $\begin{array}{l}\text { Natural science } \\
\text { (applied) }\end{array}$ & Materials Science & Biomaterials & 10000 \\
\hline Formal sciences & Mathematics & Algebra and Number Theory & 5935 \\
\hline Medicine & Medicine & Anesthesiology and Pain Medicine & 6166 \\
\hline Health Sciences & Nursing & Advanced and Specialized Nursing & 3042 \\
\hline Social Sciences & Social Sciences & Communication & 5981 \\
\hline
\end{tabular}

The year 2014 was chosen as the publication year of the articles to be analysed. A recent year was needed to increase the chance that Mendeley users registered as students would have been students when they registered the article. This is because Mendeley only provides the current status of users with an article in their library, irrespective of when the article was added. Mendeley also does not report when an article was added to any library. Thus a lecturer with an old paper in their library may have been a student when they added it but there is no way to check this. The year 2015 was not chosen so that all articles had, in theory, the chance to be added to a course syllabus by instructors. This is important because much undergraduate reading in some subject areas may be instructor-directed.

For each of the twelve subjects, details of up to 10,000 journal articles from 2014 were downloaded from Scopus. For subjects with fewer than 10,000 articles, this is a complete list. For subjects with more than 10,000 , the complete set could not be extracted from Scopus because of restrictions in its interface but the first 5,000 and last 5,000 from the year were downloaded instead so that the combination provided a time-balanced subset. Only documents of type journal article were included for consistency between subjects. This excludes review articles and editorials as well as non-journal documents, such 
as book chapters and monographs. The result of this stage was therefore a set of up to 10,000 journal articles from 2014 for each of 12 different Scopus subject categories.

The number of Mendeley users registering each article, its Mendeley reader count, was extracted from the Mendeley Applications Programming Interface (API). This is a computing service provided by Mendeley for the free large-scale downloading of information from its database. The API was accessed via the free software Webometric Analyst, which used the 12 lists of Scopus publications and submitted a query for each article to Mendeley. Matching articles were found in Mendeley using both author/title/publication year searches (i.e., querying the article by name, author and publication year) and DOI searches (i.e., querying the article by DOI), with the results of both combined since neither method is perfect (Zahedi, Haustein, \& Bowman, 2014). Combining the two querying methods is helpful because not all users will have entered the DOls of their references and some abbreviate titles or make errors entering them, whereas the DOI searches can still retrieve such records. Although articles can be registered in Mendeley by users without reading them first, most users have read, or intend to read, their registered articles (Mohammadi, Thelwall, \& Kousha, 2016) and so it is reasonable to interpret Mendeley data as readership counts. The end result of this stage was therefore a set of Mendeley readership information for each article from each of the 12 Scopus categories.

Mendeley records the user-entered occupation of each member and returns the total number of readers in each occupational category for each article. The self-reported occupational categories of Student>Undergraduate and Student>Master were used for the analysis. The additional category Student>Postgraduate may also have been selected by some master's degree students but was not incorporated into the analyses. This category could also include some PhD students as well as those studying postgraduate certificates or professional qualifications. This may therefore tend to blur distinctions in the results between master's students and PhD students.

For the first two research questions the geometric mean number of readers of Mendeley articles was calculated for bachelor's degree students and for master's degree students. Geometric means were calculated as measures of average rather than arithmetic means because Mendeley reader data is highly skewed (Thelwall \& Wilson, 2016) and arithmetic means are inappropriate for skewed data. Confidence intervals were calculated using the standard normal distribution formula on the log transformed data generated when calculating the geometric means, following standard practice (Thelwall, 2016).

For the third and fourth research questions, the proportion of each type of reader recorded in Mendeley was calculated separately for each subject area, after excluding the Librarian and Other categories. The categories cover students, researchers and academic faculty. Although some academic faculty may have teaching-only posts (e.g., some lecturers), it seems reasonable to assume that most faculty members have research as at least part of their jobs.

\section{Results}

There are large disciplinary differences in the average number of Mendeley student readers per article (RQ1, RQ2), from Algebra and Number Theory (0.02 Bachelor, 0.05 Master) to Aging (1.09 Bachelor, 1.72 Master), which is a disciplinary difference of 50 times larger for bachelor's degree students and 32 times larger for master's degree students (Figure 1). The differences between most pairs of subjects are statistically significant, as evidenced by non- 
overlapping 95\% confidence intervals. Thus there are huge disciplinary differences in the extent to which academic articles are recorded by students in Mendeley.

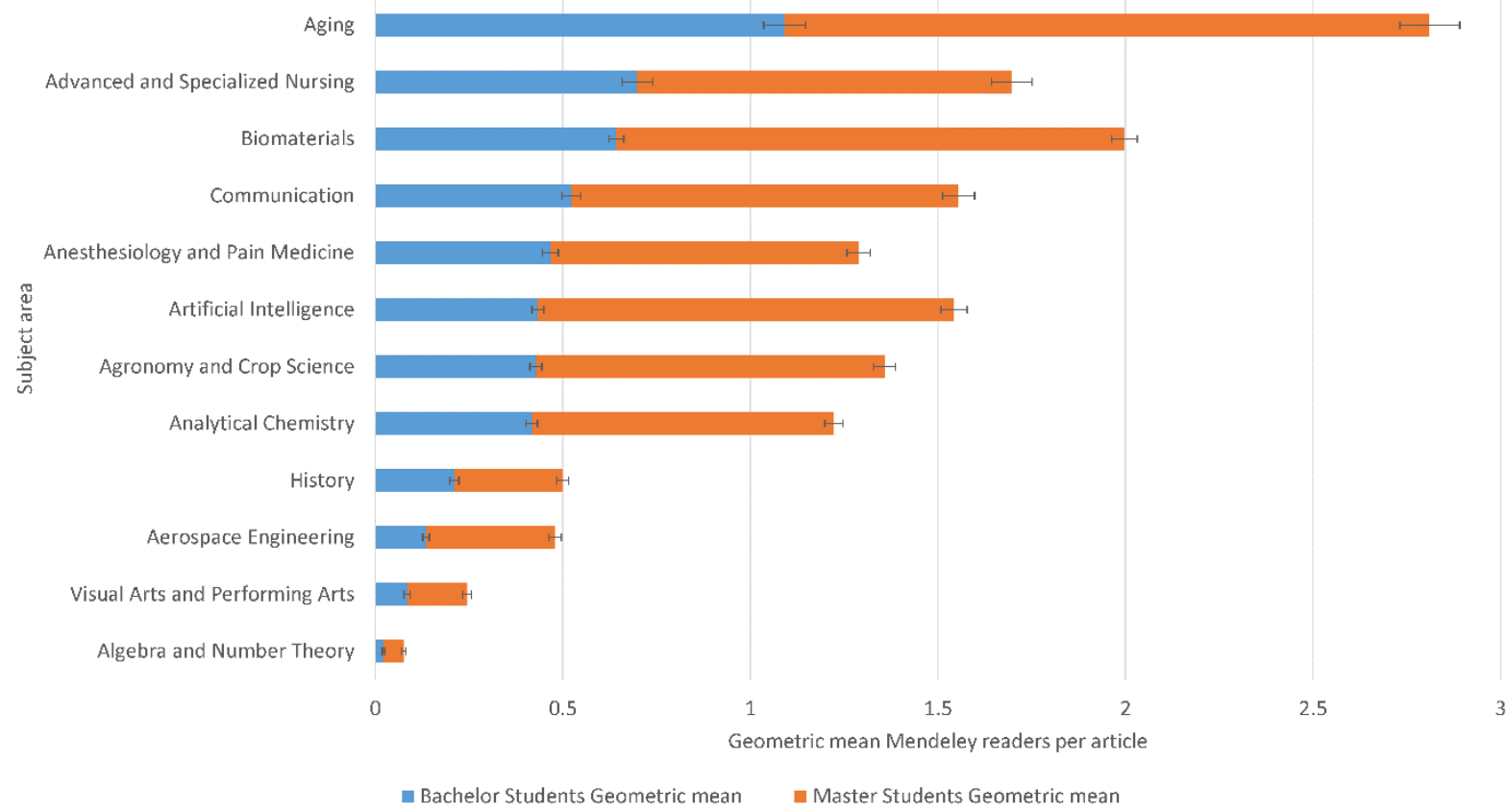

Figure 1. The average (geometric mean) number of Bachelor and Master student Mendeley readers per article for articles published in 2014 in 12 Scopus categories. Subjects are in ascending order of geometric mean bachelor student readers per article. Error bars indicate $95 \%$ confidence intervals for the geometric mean.

The proportion of student Mendeley readers of articles (RQ3, RQ4) differs by subject from Algebra and Number Theory (4\% Bachelor; 10\% Master) to Advanced and Specialised Nursing (12\% Bachelor; 19\% Master), which is 3 times larger for bachelor's degree students and 2 times larger for master's degree students (Figure 2). Algebra and Number Theory is an exception, however, and for the remaining subjects the number of student readers is roughly in proportion to the number of researching readers within each subject area. Thus the results do not support the hypothesis that journal articles have a particularly high direct value in education in some areas of scholarship, at least in comparison to their value for researchers. 


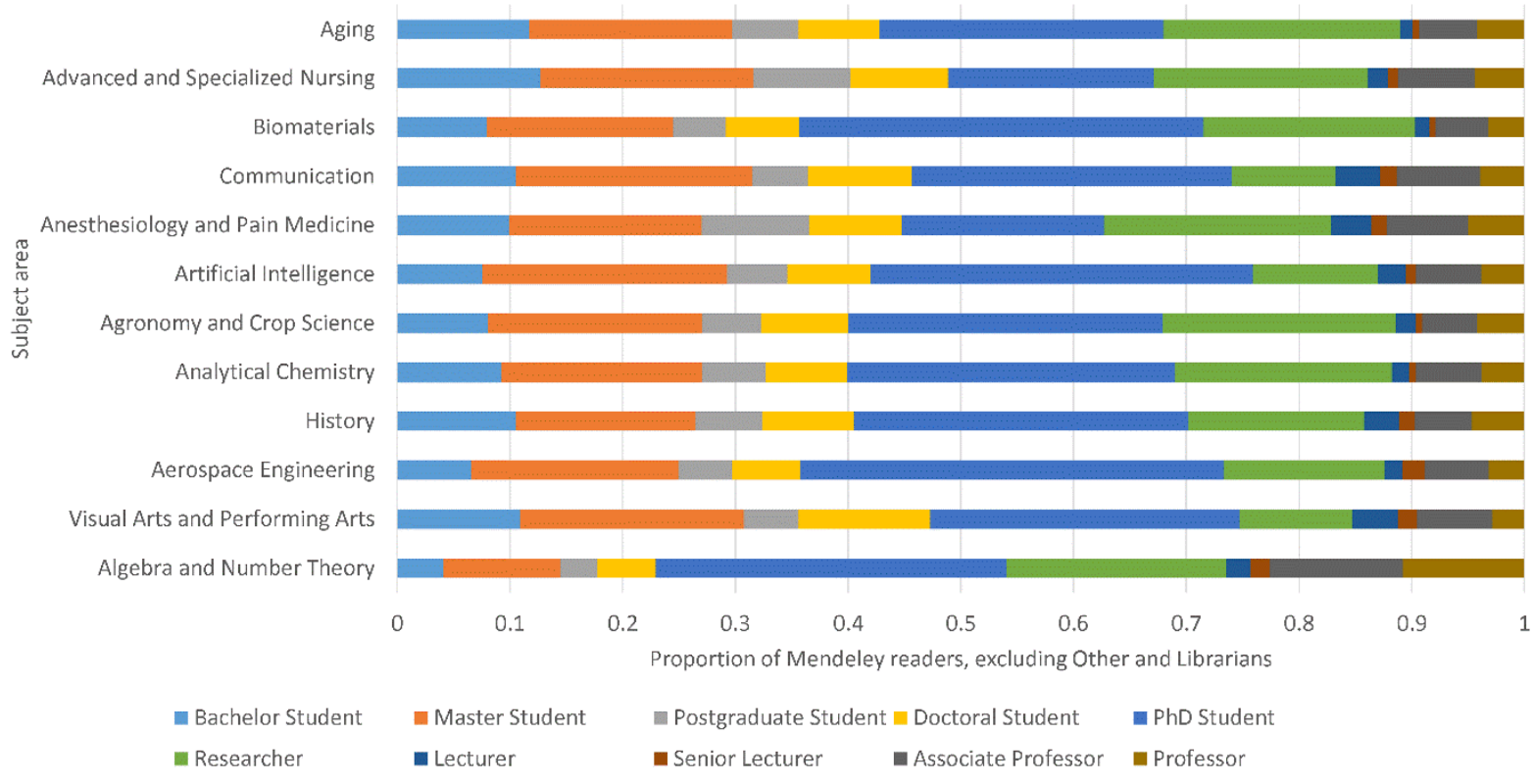

Figure 2. The proportions of different types of reader for articles published in 2014 in 12 Scopus categories. The categories are the self-reported current statuses of Mendeley readers, as recorded in the site, and exclude the Librarian and Other classifications. Subjects are in ascending order of average (geometric mean) bachelor student readers per article.

\section{Discussion}

This study has a number of limitations, including taking self-reported reader occupations at face value. In some cases, the apparently student readers are likely to be researchers that have not changed their Mendeley status since graduating. The results only apply to Mendeley readers, which are likely to be a biased subset of all readers. For example, they may be younger, more technologically literate, and more focused on careers in research after their studies. The assumption that the similar proportions of students and researchers use Mendeley in each subject is probably also not true. It seems likely that in essay-based subjects a relatively higher proportion of students would find Mendeley useful for its reference management role. Another important limitation is that other subjects within the broad areas selected may give different results. All areas of research have unique components and therefore subjects that seem to an outsider to be similar may have substantial differences that affect the relationship between research and education.

The pure mathematics outlying subject, Algebra and Number Theory, had the smallest number of student readers of articles and the fewest students relative to the number of researchers. In this subject, only 174 out of 5935 articles (3\%) had at least one undergraduate reader and $397(7 \%)$ had at least one Master reader. It is perhaps surprising that any pure mathematics articles had undergraduate readers, given the typically hierarchical nature of the subject. The most popular article, with 8 Bachelor and 15 Master readers, was Practical graph isomorphism, II, in the Journal of Symbolic Computation. This started by summarising the state of the art in a problem area in (relatively) basic language and so seems particularly accessible to undergraduates. This article was also highly cited (75 citations) suggesting that it was both introductory and important. Thus, some Algebra and Number Theory journals occasionally publish articles that are in part accessible to students, although these are probably a small minority. 
Arts and humanities journal articles could be expected to attract more student readers than other subjects because these areas are less hierarchical and hence journal articles could be more accessible to non-researchers. Moreover, the essay-based nature of the humanities lends itself to the use of Mendeley by students. Nevertheless, only 509 out of 6096 Visual Arts and Performing Arts journal articles (8\%) had at least one undergraduate reader and $878(14 \%)$ had at least one Master reader. This could be explained by low use of Mendeley the arts and humanities, which is plausible because the same proportion of readers are students as for most other subject areas. The articles within this subject all seemed to be accessible to undergraduates but were often specific to a degree that may narrow the potential audience. Specific topics, such as, Michael Glabas Tarchaneiotes - The ktetor of the Treskavac Monastery, and Exegetical imagery for King Manuel I of Portugal: Solomon's temple in Nicholas of Lyra's Postilla seem unlikely to attract a wide readership. Thus the explanation for arts scholarship could be that its diversity means that the audience for individual journal articles, both researchers and students, is limited.

For the humanities subject, History, 1396 out of 6967 articles (20\%) had an undergraduate reader and 1667 (24\%) had at least one Master reader. Although the average number of student readers per article was lower than all health, medical, natural and social sciences, the proportion of undergraduate readers was similar and so the reason for the low numbers could be low uptake of Mendeley in the humanities. As for the arts, the articles seem to be accessible to undergraduates in terms of contents, but are perhaps too specific to attract their attention as relevant to their work. Two examples are The Western River Steamboat Heroine, 1832-1838, Oklahoma, USA: Construction and Paradoxical virtues: Intellectuals between the court and the academy in agostino mascardi's che la corte é vera scuola non solamente della prudenza, ma delle virtù morali (1624).

Aerospace Engineering has the third fewest student readers and a low proportion of undergraduate readers. Out of 7155 articles, 1016 (14\%) had at least one undergraduate reader and 2029 (28\%) had at least one Master reader. This category contained many large Chinese journals with few readers and so, assuming a level of homophily in interest in articles and low use of Mendeley in China, this would explain the low overall results for this category.

Aging is an outlier for its high average numbers of readers per article, with 1666 out of 2666 (62\%) having at least one undergraduate reader and 1962 (74\%) having at least one Master reader. This is a relatively high citation category, with 5.9 citations per article (in contrast to 4.6 for the second category, Advanced and Specialised Nursing). The Aging subject also has more student readers per citation ( 0.76 in comparison to 0.70 for Advanced and Specialised Nursing) and so its high number of student readers may be due to high interest in the topic (as evidenced by citations) and high interest from students, perhaps via their teachers. The topic of aging is of growing interest as the life expectancy of the world's population increases and perhaps also has a direct personal connection to many students (and researchers) through their elderly relatives.

The results here are relevant only to the reading of journal articles by students. Most higher education is probably research-informed or traceable in some way to research and so the fact that students do not read research articles does not imply that research does not inform education. Instead, in some subjects, such as pure maths, journal articles might necessarily be too difficult for undergraduates to understand with textbooks playing a critical role in translating the findings into a digestible format, perhaps through amalgamation with other results into a coherent, structured course. In a similar way, journal 
articles in the arts and humanities may be stepping stones towards monographs, which are more central to the discipline. In performance arts, journal articles can inform expert practice and their knowledge may be transferred aurally or by example to students. Thus, the findings should not be interpreted as relating to the use of research knowledge overall within education.

\section{Conclusions}

The overall findings of this study are negative. With perhaps small exceptions for Nursing (health sciences) and Aging (life sciences), there are no areas for which the results would support a strong disciplinary claim for the direct added educational value of research articles in the sense of being frequently read by undergraduate or master's students. Although there are substantial differences in the numbers of student readers of articles, these are broadly in line with the overall level of readership of the articles, except for Algebra and Number Theory. The data therefore do not support a conclusion that any particular subject area produces research that is of unusually high value within higher education, compared to its value for research.

The lack of a positive result is perhaps surprising for the arts and humanities, where journal articles seem likely to be understandable to undergraduates because knowledge building is less hierarchical (Hyland, 2004) and so students would not be less likely to be confronted with unknown theories, concepts, mathematical formulae, or methods that would obstruct their understanding. Moreover, the importance of educational value for scholarship seems to be taken for granted in the arts and humanities (e.g., Gillies, 2011). A possible explanation is that monographs are the main scholarly outputs in the humanities, and non-standard outputs such as music and performances are the norm in the arts, and so students may access these instead of journal articles. Alternatively, the result may be due to the highly level of specificity of these outputs, which often focus on a single work or person. It is also possible that the outputs produced by arts and humanities scholars that are most valuable in education are of other types, such as monographs, performances or techniques. A logical direction for future research is therefore to find ways to assess how arts and humanities scholars generate educational value from their scholarship. This will help to clarify the relationship between teaching and disciplinary research, both in terms of how direct it is and how extensive. It would also be useful to revisit the findings if detailed information becomes available about the proportion of Mendeley users in different academic subjects and the relative proportions of students and researchers using Mendeley in different subjects.

\section{References}

Ambrose, S. A., Bridges, M. W., DiPietro, M., Lovett, M. C., \& Norman, M. K. (2010). How learning works: Seven research-based principles for smart teaching. New York, NY: John Wiley \& Sons.

Becher, T., \& Trowler, P. R. (2001). Academic tribes and territories: Intellectual inquiry and the culture of disciplines ( 2 ed). Milton Keynes, UK: Open University Press

Caldwell, K., Henshaw, L., \& Taylor, G. (2011). Developing a framework for critiquing health research: an early evaluation. Nurse education today, 31(8), e1-e7.

Gillies, M. (2011). The public value of the humanities (book review). The Times Higher Education Supplement, 1991 (Mar 24), p.58. 
Glänzel, W., \& Schubert, A. (2003). A new classification scheme of science fields and subfields designed for scientometric evaluation purposes. Scientometrics, 56(3), 357367.

Greenbank, P., \& Penketh, C. (2009). Student autonomy and reflections on researching and writing the undergraduate dissertation. Journal of Further and Higher Education, $33(4), 463-472$.

Gunn, W. (2013). Social signals reflect academic impact: What it means when a scholar adds a paper to Mendeley. Information Standards Quarterly, 25(2), 33-39.

Hattie, J., \& Marsh, H. W. (1996). The relationship between research and teaching: A metaanalysis. Review of educational research, 66(4), 507-542.

Haustein, S., Larivière, V., Thelwall, M., Amyot, D., \& Peters, I. (2014). Tweets vs. Mendeley readers: How do these two social media metrics differ? IT-Information Technology, 56(5), 207-215.

Haustein, S., \& Larivière, V. (2014). Mendeley as a source of readership by students and postdocs? Evaluating article usage by academic status. Proceedings of the IATUL Conferences, Paper http://docs.lib.purdue.edu/cgi/viewcontent.cgi?article=2033\&context=iatul

Horsley, M., Knight, B. A., \& Huntly, H. (2010). The role of textbooks and other teaching and learning resources in higher education in Australia: change and continuity in supporting learning. International Association for Research on Textbooks and Educational Media, 3(2), 43-61

Hyland, K. (2004). Disciplinary discourses: Social interactions in academic writing. MI: Ann Arbor, MI: University of Michigan Press.

Jenkins, A., Healey, M., \& Zetter, R. (2007). Linking teaching and research in disciplines and departments. York, UK: The Higher Education Academy.

Lynch, M., \& Bogen, D. (1997). Sociology's asociological "core": An examination of textbook sociology in light of the sociology of scientific knowledge. American Sociological Review, 62(3), 481-493.

Kousha, K., \& Thelwall, M. (2008). Assessing the impact of disciplinary research on teaching: An automatic analysis of online syllabuses. Journal of the American Society for Information Science and Technology, 59(13), 2060-2069.

Merton, R. K. (1973). The sociology of science: Theoretical and empirical investigations. Chicago, IL: University of Chicago Press.

Mohammadi, E., Thelwall, M., Haustein, S., \& Larivière, V. (2015). Who reads research articles? An altmetrics analysis of Mendeley user categories. Journal of the Association for Information Science and Technology, 66(9), 1832-1846. doi: 10.1002/asi.23286

Mohammadi, E., Thelwall, M. \& Kousha, K. (2016). Can Mendeley bookmarks reflect readership? A survey of user motivations. Journal of the Association for Information Science and Technology, 67(5), 1198-1209. doi:10.1002/asi.23477

Myers, G. A. (1992). Textbooks and the sociology of scientific knowledge. English for Specific purposes, 11(1), 3-17.

O'Brien, J. G., Millis, B. J., \& Cohen, M. W. (2009). The course syllabus: A learning-centered approach. New York, NY: John Wiley \& Sons.

Thelwall, M. \& Wilson, P. (2016). Mendeley readership Altmetrics for medical articles: An analysis of 45 fields, Journal of the Association for Information Science and Technology, 67(8), 1962-1972. doi:10.1002/asi.23501 
Thelwall, M. (2016). The precision of the arithmetic mean, geometric mean and percentiles for citation data: An experimental simulation modelling approach. Journal of Informetrics, 10(1), 110-123. doi:10.1016/j.joi.2015.12.001

Todd, M., Bannister, P., \& Clegg, S. (2004). Independent inquiry and the undergraduate dissertation: perceptions and experiences of final-year social science students. Assessment \& Evaluation in Higher Education, 29(3), 335-355.

Van Noorden, R. (2014). Online collaboration: Scientists and the social network. Nature, 512(7513), 126-129.

Verburgh, A., Elen, J., \& Lindblom-Ylänne, S. (2007). Investigating the myth of the relationship between teaching and research in higher education: A review of empirical research. Studies in Philosophy and Education, 26(5), 449-465.

Whitley, R. (2000). The intellectual and social organization of the sciences. Oxford, UK: Oxford University Press.

Zahedi, Z., Haustein, S. \& Bowman, T. (2014). Exploring data quality and retrieval strategies for Mendeley reader counts. Presentation at SIGMET Metrics 2014 workshop. http://www.slideshare.net/StefanieHaustein/sigme-tworkshopasist2014 